\title{
Оптические и структурные свойства наноструктур Ag и c-Si, формирующихся в процессе металл-стимулированного химического травления кремния
}

\author{
(С) Ю.А. Жарова, В.А. Толмачев, С.И. Павлов \\ Физико-технический институт им. А.Ф. Иоффе Российской академии наук, \\ 194021 Санкт-Петербург, Россия \\ E-mail: piliouguina@mail.ioffe.ru
}

(Поступила в Редакцию 20 ноября 2018 г.

В окончательной редакции 27 ноября 2018 г.

Принята к публикации 27 ноября 2018 г.)

Работа, состоящая из двух частей, посвящена изучению особенностей трехстадийного процесса металлстимулированного химического травления кремния (МСXТ), используемого для получения кремниевых нанонитей. Ранее нами было проведено исследование слоя самоорганизующихся наночастиц серебра, осаждаемых химическим методом из раствора на поверхности монокристаллического кремния $(c-\mathrm{Si})$ (стадия $1 \mathrm{MCXT),} \mathrm{а} \mathrm{в} \mathrm{настоящей} \mathrm{работе} \mathrm{-} \mathrm{наноструктур} \mathrm{Si}$, формируемых на стадиях 2 и 3. С помощью спектральной эллипсометрии (длины волн $\lambda=250-900$ нм) определены псевдодиэлектрические функции наноструктур и проведено их сопоставление для всех трех стадий процесса МСХТ. Кроме того, для наноструктур Si вычислены параметры слоев (толщина и доля пустот) в многослойной оптической модели с использованием приближения эффективной среды Бруггемана и подгоночных процедур.

DOI: 10.21883/FTP.2019.04.47459.9024

\section{1. Введение}

Существует большое количество методов создания кремниевых наноструктур. Все они делятся на две большие группы: восходящие и нисходящие технологии. Восходящие технологии характеризуются формированием наноструктур по схеме снизу-вверх (механизм паржидкость-твердое тело), а нисходящие, напротив, по схеме сверху-вниз, путем травления пластин. Одним из таких методов является метод металл-стимулированного химического травления (МСXТ) кремния [1-3], сравнительно молодой, но набирающий популярность. Метод основан на селективном химическом вытравливании кремния с использованием осажденных (или напыленных) частиц благородного металла в качестве катализатора и последующего травления в растворе на основе HF. Схема трехстадийного процесса MCXT представлена на рис. 1. Электрохимические реакции (окислительно-восстановительные) протекают непосредственно под частицами металла, который является источником положительно заряженных ионов, необходимых для травления кремния. В результате образуются вертикальные пустоты (поры), а кремний, не покрытый частицами, остается не протравленным, и таким образом формируется массив кремниевых наноструктур в виде слоя так называемых кремниевых нанонитей (КНН) (рис. 2).

Морфология получаемых КНН зависит от размера, формы, упаковки наночастиц металла и условий травления. К настоящему времени в литературе представлены исследования в основном со слоями нанонитей высотой $>1$ мкм, что связано с желанием иметь толщину слоя, обеспечивающую достаточно большую интенсивность оптического отклика от исследуемой структуры при проведении оптических измерений с помощью спектрофотометрии, рамановской спектроскопии, фотолюминесцентных методов и других традиционных методик для исследования нанослоев. Правда, из-за сильного рассеяния света на длинных нитях зеркально отраженный пучок существенно слабеет и не дает хороших спектров [4]. Для исследования наноразмерных объектов необходимо использовать высокочувствительные и информативные методы диагностики, к которым относится спектральная эллипсометрия [5], к тому же являющаяся неконтактной, неразрушающей и невозмущающей методикой. Слои КНН высотой < 1 мкм исследовались мало (см. [6,7]), хотя в работе [8] авторы с помощью спектральной эллипсометрии исследовали слои КНН высотой от 170 нм и более. Для исследования особенностей метода МСХТ желательно иметь информацию о начальных этапах роста нитеобразной структуры с первых моментов каталитического травления. Структуры, формирующиеся на ранней стадии процесса МСXТ, влияют на дальнейший рост КНН и их свойства.

С этой точки зрения цель данной работы заключалась в исследовании морфологии и оптических свойств слоев кремниевых наноструктур на самом раннем этапе их формирования, в определении псевдодиэлектрических функций, их сопоставлении и анализе на трех стадиях процесса МСХТ. При моделировании использовалось приближение эффективной среды в многослойной структуре и проводилось сравнение с экспериментом. 

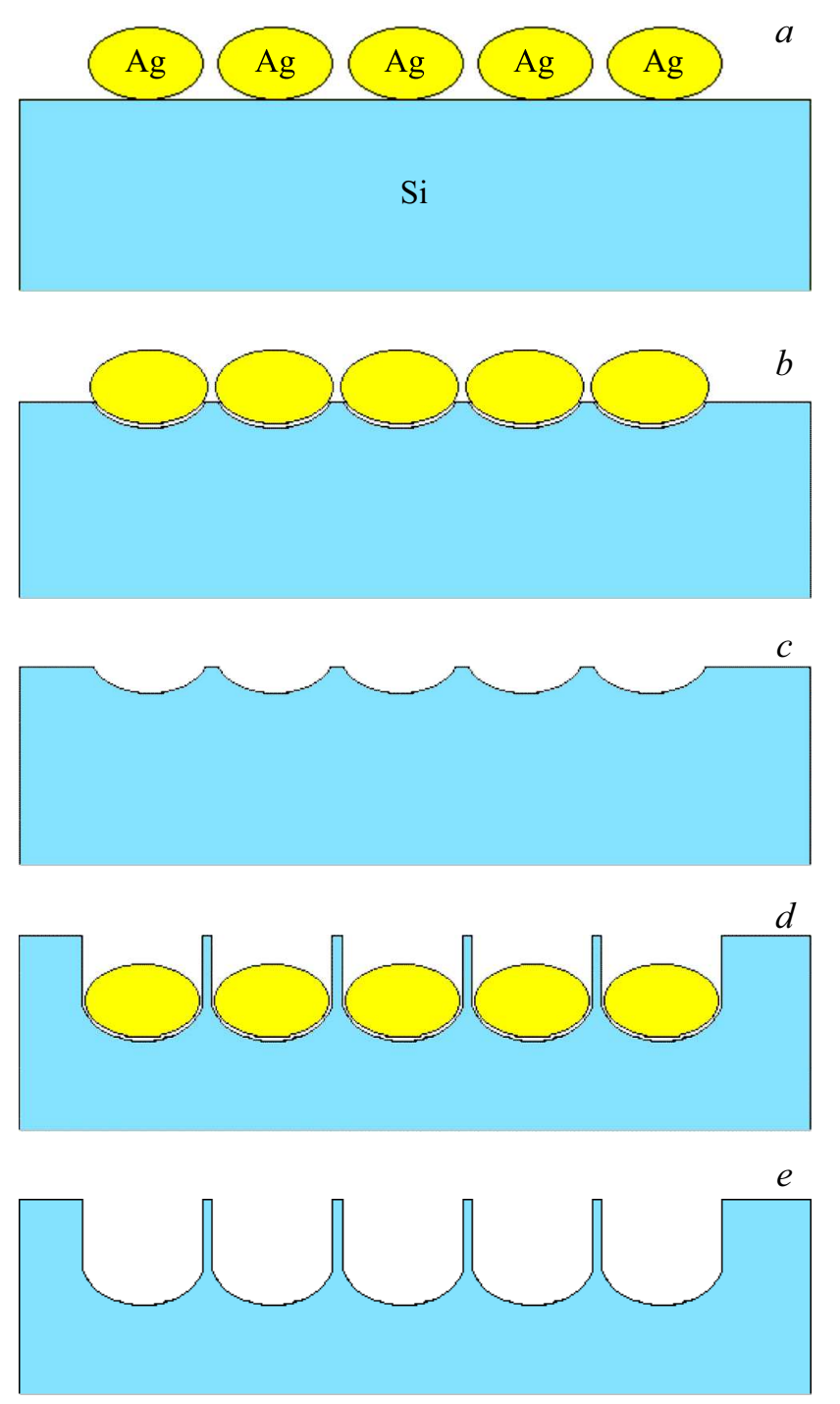

Рис. 1. Схема трех стадий процесса МСXТ: $a$ - осаждение наночастиц серебра (маски-катализатора); $b, c$ - каталитическое травление $\mathrm{Si}$ в течение $t=5(b)$ и 10 с $(d)$ с образованием слоя нитеобразной наноструктуры; $c, e-$ после удаления серебра.

\section{2. Методика эксперимента}

В работе использовались кремниевые пластины $p$-Si (100) с удельным сопротивлением 1Ом·см и трехстадийный процесс МСXТ [1,2]. После осаждения наночастиц серебра (стадия 1) образцы травились (стадия 2) (рис. $1, b, d)$ в растворе $\mathrm{HF}+\mathrm{H}_{2} \mathrm{O}_{2}$ с различной продолжительностью $t$. На последней стадии частицы $\mathrm{Ag}$ химически удалялись (рис. 1,c,e). Микроскопические изображения были получены с помощью растрового электронного микроскопа (РЭМ) JSM 7001F (Jeol, Япония).

Оптические измерения проводились с помощью спектрального эллипсометра „Спектроскан“ [9] в диапазоне длин волн $\lambda=250-900$ нм на воздухе, при угле падения излучения относительно нормали к поверхности $\varphi=70^{\circ}$. Определялись эллипсометрические углы $\psi$ и $\Delta$, входящие в основное уравнение эллипсометрии [10]

$$
\rho=r_{p} / r_{s}=\operatorname{tg} \psi \exp (i \Delta),
$$

где $\operatorname{tg} \psi=\left|r_{p}\right| /\left|r_{s}\right|$ - отношение комплексных коэффициентов отражения $r_{p}$ и $r_{s}$, а $\Delta=\delta r_{p}-\delta r_{s}$ - относительное изменение фазы, испытываемое при отражении между $p$ - и $s$-компонентами.

Уравнение (1) позволяет решать прямую задачу эллипсометрии, с его помощью можно рассчитывать и анализировать поведение эллипсометрических углов для разных моделей оптических структур, исходя из их материальных параметров и углов падения $\varphi$.

\section{3. Эллипсометрическое исследование слоев наноструктур Ag и $c$-Si на поверхности кремния}

На второй стадии травление $\mathrm{Si}$ происходило под частицами металла (рис. $1, b, d$ ), поэтому наночастицы $\mathrm{Ag}$ по мере продвижения фронта травления перемещались вместе с ним, углубляясь в кремний. На рис. 2 приведено изображение слоя кремниевых нанонитей высотой $d_{\mathrm{SiNWs}}=250-300$ нм, а на рис. 3 - изображения структур, сформированных с временами травления $t=5$ и $10 \mathrm{c}$.

После травления в течение $t=5$ с на поверхности $\mathrm{Si}$ появилась заметная шероховатость и отдельно стоящие кремниевые холмики разной высоты (рис. 3,a). В данном случае удалось зафиксировать момент самого начала травления, когда глубина структуры соизмерима с размером наночастиц серебра. После травления в течение $t=10$ с видно развитие структуры и появление зародышей кремниевых нитей большей высоты (рис. $3, b$ ).

Эллипсометрическое исследование слоя КНН, представленного на рис. 2 ( $d_{\mathrm{SiNWs}} \approx 250$ нм $)$, было затруднительно, так как падающий пучок достаточно сильно

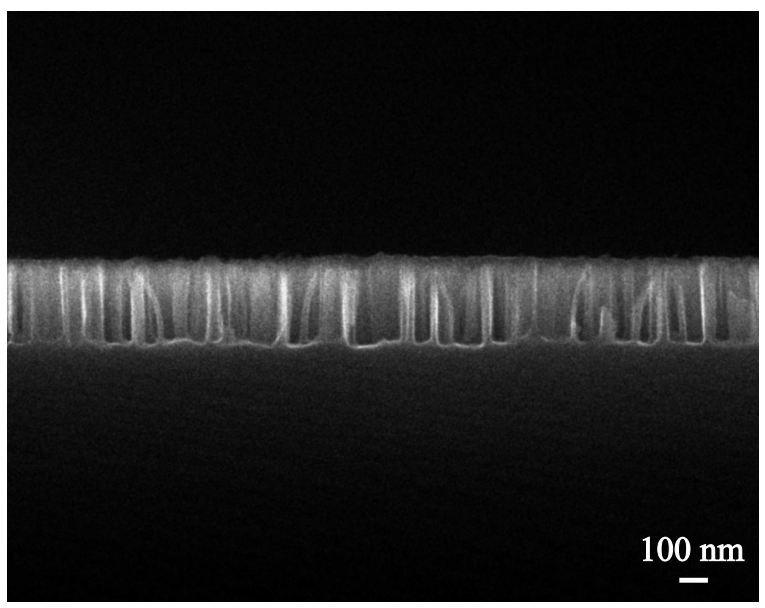

Рис. 2. РЭМ-изображение слоя нанонитей из монокристаллического $\mathrm{Si}(c-\mathrm{Si})$, сформированных на поверхности $c$ - $\mathrm{Si}$ (высота КНH $\sim(250-300)$ Hм $)$. 

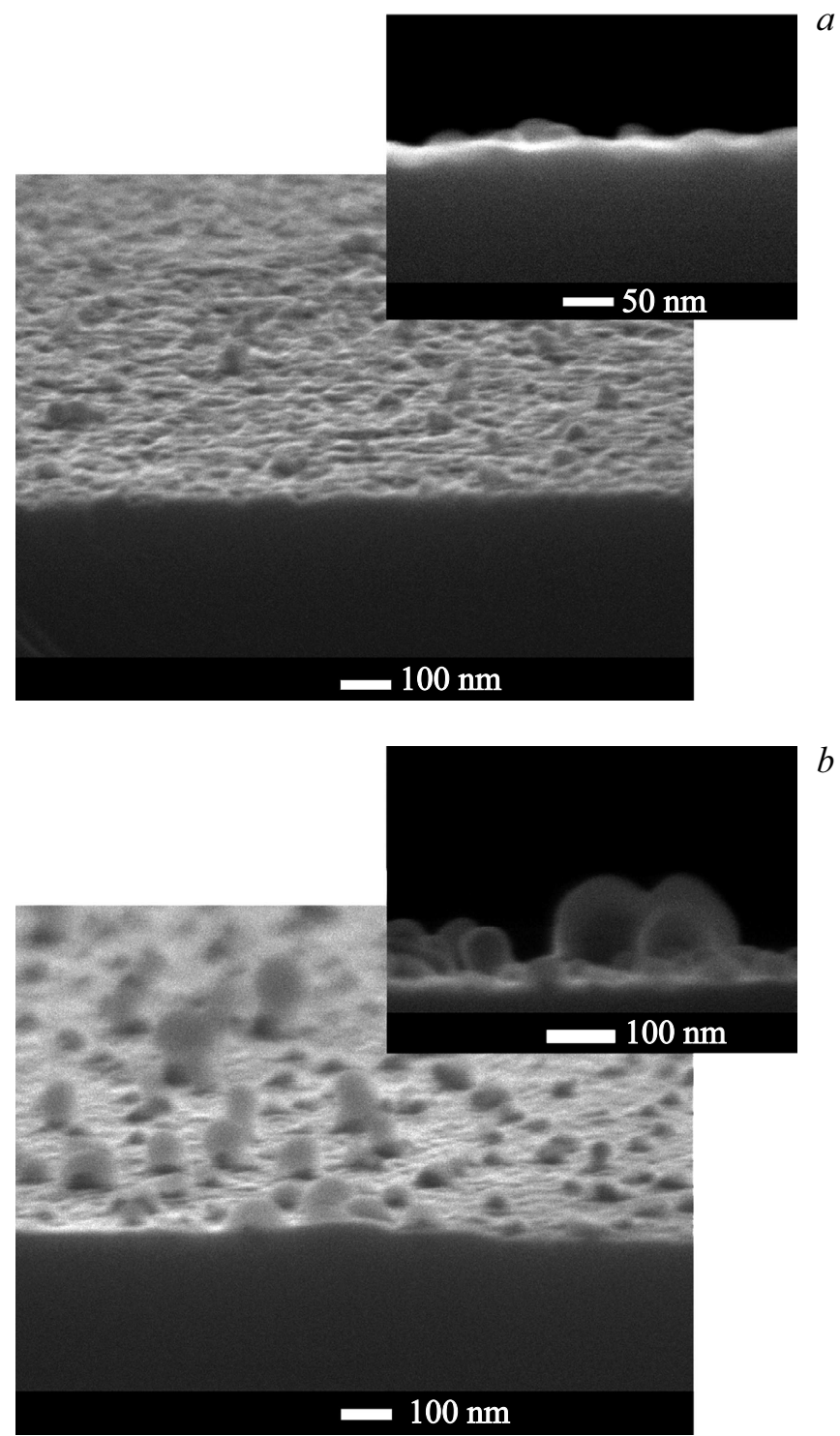

Рис. 3. РЭМ-изображение поперечного сечения и вид под углом для слоев наноструктур из $c-\mathrm{Si}$, полученных в результате травления в течение $t=5(a)$ и $10 \mathrm{c}(b)$.

рассеивался после отражения; поэтому далее анализировались образцы травления с $t=5$ и 10 с. На рис. $4, a, b$ представлены экспериментальные спектры элипсометрических углов до травления и после травления в течение $t=5$ с (стадия 2 МСХТ), между которыми наблюдается лишь незначительное различие. В данном эксперименте травление происходит на небольшую глубину и частицы серебра не погружаются полностью в кремний (схема на рис. $1, b)$, сохраняя границу „наночастица $\mathrm{Ag}-$ воздух“, причем это относится к границе как с внешней средой, так и между частицами. При этом в спектре эллипсометрических углов $(\psi$ и $\Delta)$ резонансный пик при $\lambda=326$ нм от Ag [1] и его форма почти полностью сохраняются. После травления образца с наночастицами $\mathrm{Ag}$ в течение $t=10$ с наблюдается достаточно сильное уменьшение амплитуды и размытие пика (по сравнению с исходным ярко выраженным резонансом) (рис. 5, $a, b$ ), что может быть объяснено образованием двухслойной структуры, в нижней части которой (на дне структуры) находится источник резонанса - наночастицы Ag, но уже разделенные не воздухом, а нанонитями $\mathrm{Si}$ (рис. 1,d). Очевидно, что замена среды, окружающей частицу, с диэлектрической проницаемостью $\varepsilon$ воздуха (рис. 1,a) на $c$-Si другой $\varepsilon$ может приводить к существенному изменению формы резонансного пика. Кроме того, над этим слоем с частицами $\mathrm{Ag}$ находится верхний „этаж“ в виде слоя из смеси нанонитей $\mathrm{Si}$ и воздуха, который создает дополнительные интерференционные особенности в суммарном спектре этой двухслойной композитной структуры, что также может способствовать размытию резонансного пика.

После удаления серебра (стадия 3 МСХТ) произошли существенные изменения эллипсометрических спектров
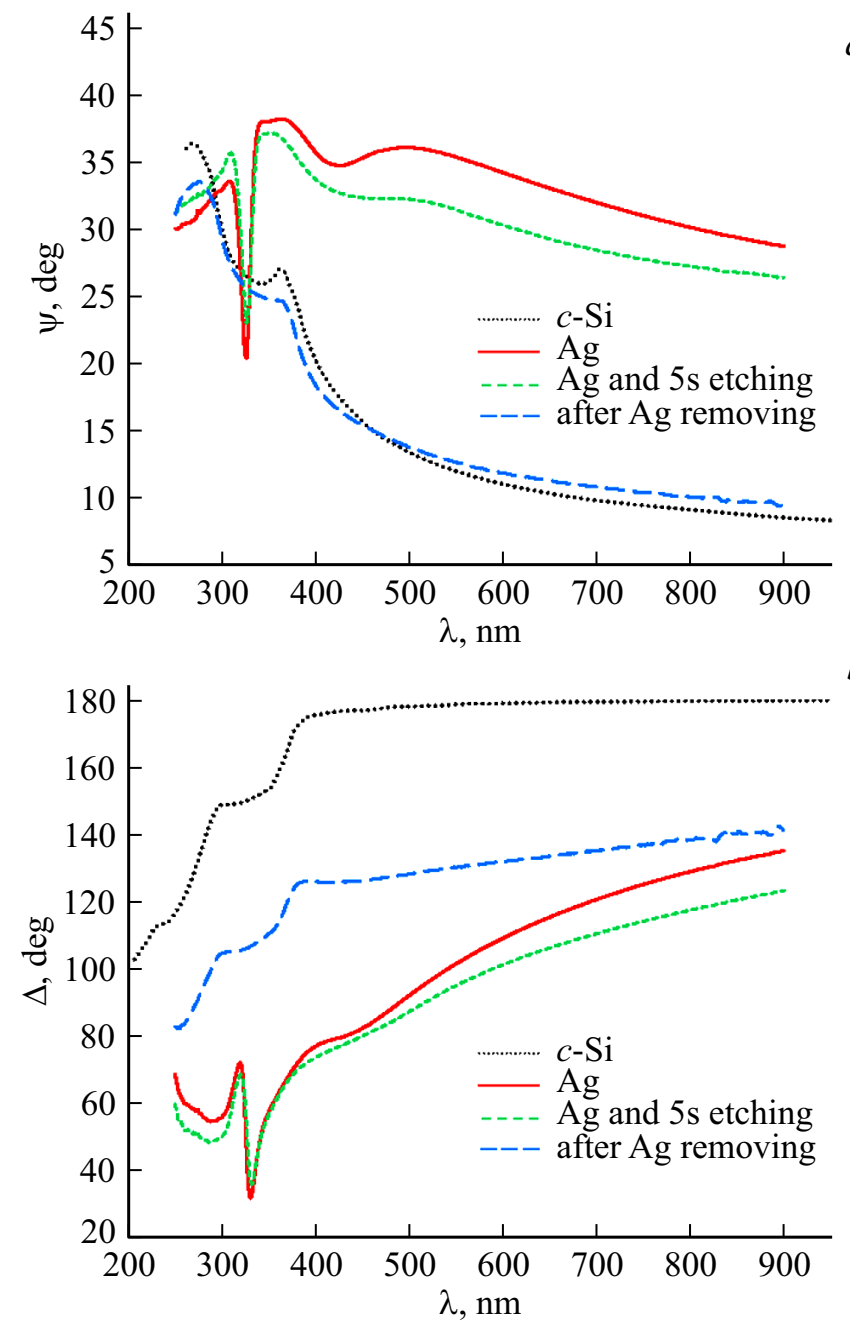

Рис. 4. Спектры измеренных эллипсометрических углов $\psi(a)$ и $\Delta(b)$ для исходной поверхности $(c-\mathrm{Si})$, для слоя из осажденных частиц серебра (Ag), слоя после МСХТ продолжительностью $5 \mathrm{c}$ (Ag and $5 \mathrm{~s}$ etching) и после удаления Ag из структуры (after Ag removing); угол падения $\varphi=70^{\circ}$. 
$\psi$ и $\Delta$ : для травления в течение $t=5$ с они трансформировались в спектры, близкие к спектрам поверхности $c-\mathrm{Si}$, и исчезли пики, присущие $\mathrm{Ag}$ (рис. 4). При травлении в течение $t=10$ с также исчезли пики, характерные для серебра, но спектры с характерными для Si критическими точками от структуры $c$-Si (рис. 4,b) [11] не появились (рис. 5).

Далее эллипсометрические спектры полученных наноструктур (рис. 4,5) были преобразованы с помощью выражения

$$
\begin{aligned}
\varepsilon & =\varepsilon_{1}+i \varepsilon_{2} \\
& =\sin ^{2} \varphi\left\{1+\left[(1-\rho)^{2} /(1+\rho)^{2}\right] \tan ^{2}(\varphi)\right\}
\end{aligned}
$$

в псевдодиэлектрические функции [10], которые представлены на рис. 6.

Полученные функции $\varepsilon_{1}$ и $\varepsilon_{2}$ (реальная и мнимая части соответственно) можно анализировать с исполь-
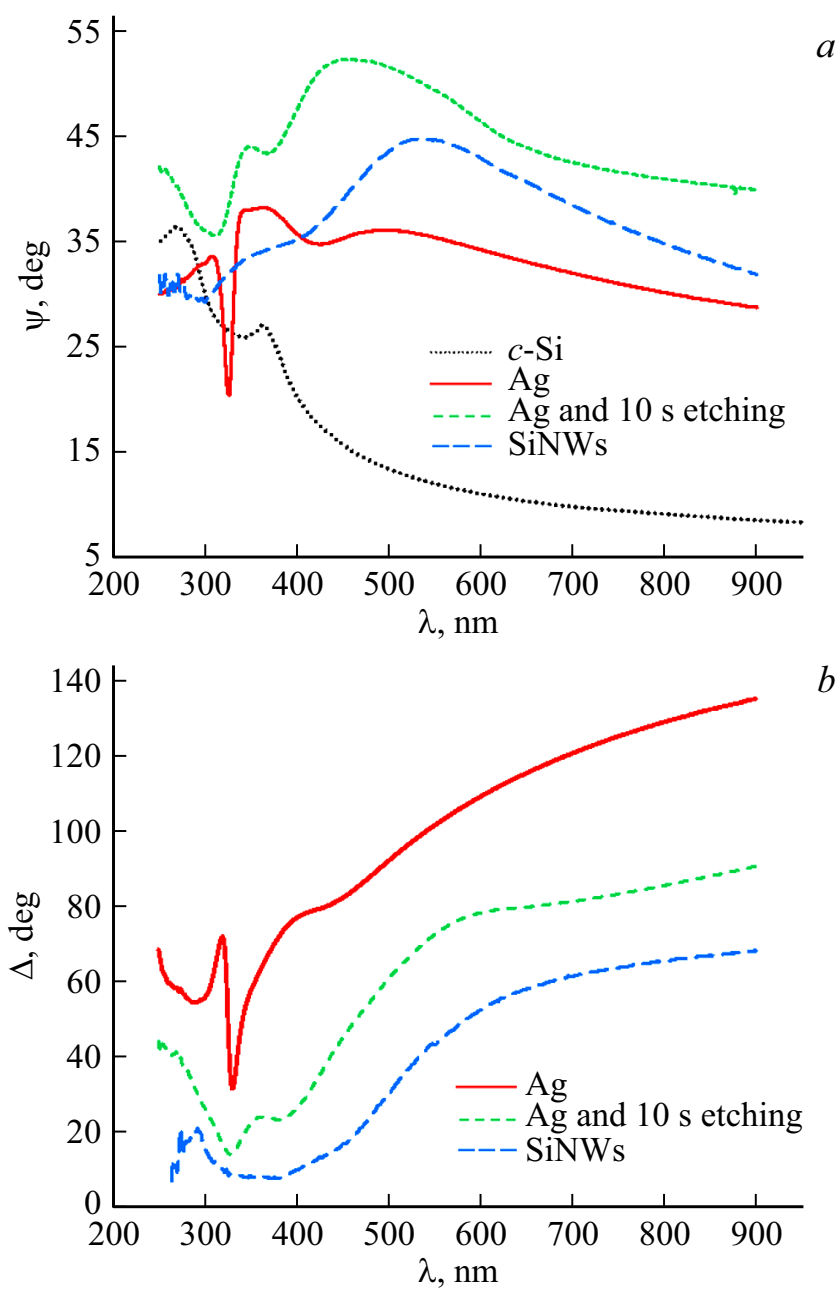

Рис. 5. Спектры измеренных эллипсометрических углов $\psi(a)$ и $\Delta(b)$ для исходной поверхности $(c-\mathrm{Si})$, слоя осажденных наночастиц серебра $(\mathrm{Ag})$, слоя КНН, сформированного в результате МCXT $t=10 \mathrm{c}$ до удаления частиц серебра из структуры (Ag and 10 s etching) и после удаления $\mathrm{Ag}(\mathrm{SiNWs})$; $\varphi=70^{\circ}$.
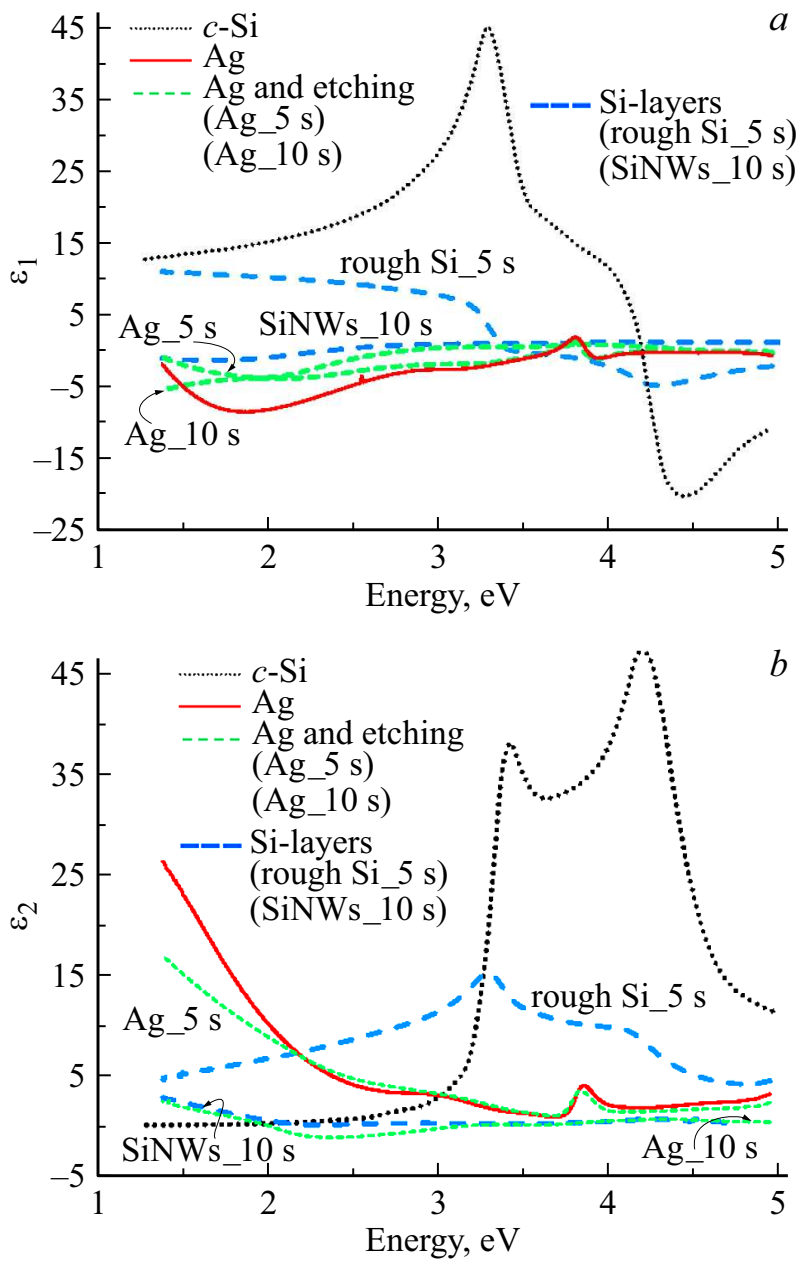

Рис. 6. Действительная $\varepsilon_{1}(a)$ и мнимая $\varepsilon_{2}(b)$ части диэлектрических функций для исходной поверхности $(c-\mathrm{Si})$, слоя осажденных наночастиц $(\mathrm{Ag})$ и формирующихся слоев $\mathrm{Si}$ наноструктуры после травления различной продолжительности (5 и $10 \mathrm{c})$ с частицами серебра (Ag_5s, Ag_10s) и после их удаления (rough $\mathrm{Si} \_5 \mathrm{~s}, \mathrm{SiNWs} \_10 \mathrm{~s}$ ).

зованием модели „внешняя среда-подложка“, несмотря на то что на РЭМ-снимках (рис. 3) слои наноструктур $\mathrm{Si}$ на поверхности хорошо просматриваются, и имеют определенную толщину. Такой подход отображает совокупность оптических свойств слоя и подложки, т.е. представляет собой модель „эффективной подложки“ с псевдодиэлектрической функцией $\varepsilon$, и используется для нанослоев на подложке. Из рис. $6, a, b$ видно, что уже при травлении в течение $t=5$ с спектры $\varepsilon_{1}$ и $\varepsilon_{2}$ для полученных структур изменились радикально по сравнению с $\varepsilon_{1}, \varepsilon_{2}$ для $c$-Si [12], не говоря о более длительном травлении $(t=10 \mathrm{c})$. Обычно исследуют спектры мнимой части $\varepsilon_{2}$, поэтому на рис. $6, b$ представлено изменение $\varepsilon_{2}$ от слоя наночастиц $\mathrm{Ag}$ к слою $\mathrm{Si}$ наноструктуры после травления при $t=5 \mathrm{c}$ и далее к тому же полученному слою, но уже без частиц Ag. Видно, что в спектре (Ag_5s) наблюдается характерный резонансный пик (энергия $E=3.8 \mathrm{eV}$ ) [1], мало 
изменившийся по сравнению с наблюдавшимся для слоя наночастиц $\mathrm{Ag}$, а в третьем спектре rough $\mathrm{Si} 5 \mathrm{~s}$ для слоя наноструктур $\mathrm{Si}$, как и ожидалось, его уже нет, появляются два пика $(E=3.4$ и 4.2 эВ), которые можно отнести к структуре $c$-Si $[11]$.

Трансформация спектров $\varepsilon_{2}$ после травления при $t=10$ с (рис. $6, b)$ происходит достаточно резко, приближаясь к спектру $\varepsilon_{2}$ без частиц Ag. В спектре $\varepsilon_{2}$ нет следов резонансных пиков от структуры объемного $\mathrm{Ag}[12]$, хотя физически частицы $\mathrm{Ag}$ там находятся на дне пор-пустот, согласно схеме на рис. $1, d$. Такая особенность свидетельствует о том, что образующийся слой наноструктур Si сильно доминирует в отраженном пучке, фактически экранируя внутренний слой наночастиц $\mathrm{Ag}$, тогда как в случае с травлением при $t=5 \mathrm{c}$ такого эффекта не наблюдается, а напротив, доминирует слой наночастиц Ag.

Далее для интерпретации эллипсометрических данных была использована другая оптическая модель, более приближенная к РЭМ-изображениям на рис. 3. Она представляет собой двухкомпонентный слой (Si-пустоты), расположенный на подложке $\mathrm{Si}$. Поскольку поперечный размер наноструктур $\mathrm{Si}$ составляет $\sim(10-20)$ нм и межнитевые расстояния не превышают $50 \mathrm{Hм}$, а используемые в эксперименте длины волн существенно больше, для анализа оптических характеристик компонентов слоя можно использовать аппроксимацию эффективной среды Бруггемана (АЭСБ) [13]:

$$
\begin{gathered}
f_{\mathrm{Si}} \frac{\left(\varepsilon_{\mathrm{Si}}-\varepsilon_{\mathrm{ef}}\right)}{\left(\varepsilon_{\mathrm{Si}}+2 \varepsilon_{\mathrm{ef}}\right)}+f_{\text {voids }} \frac{\left(\varepsilon_{\text {voids }}-\varepsilon_{\mathrm{ef}}\right)}{\left(\varepsilon_{\text {voids }}+2 \varepsilon_{\mathrm{ef}}\right)}=0, \\
f_{\mathrm{Si}}+f_{\text {voids }}=1
\end{gathered}
$$

где $f_{\mathrm{Si}}, \varepsilon_{\mathrm{Si}}$ и $f_{\text {voids }}, \varepsilon_{\text {voids }}$ - объемные фракции, комплексные диэлектрические проницаемости $\mathrm{Si}$ и воздуха соответственно, а $\varepsilon_{\text {ef }}$ - диэлектрическая проницаемость эффективной среды.

Предполагается, что слой является оптически изотропным, $\varepsilon_{\text {voids }}=1$ и величина $\varepsilon_{\mathrm{Si}}$ известна [12], неизвестными параметрами являются толщина слоя $d_{\mathrm{SiNWs}}$ и $f_{\text {voids. }}$ С помощью АЭСБ по выражению (3) для значений $f_{\text {voids }}$ рассчитывается $\varepsilon_{\text {ef }}$, а затем по формулам Френеля с учетом толщины $d$ слоя на подложке $\mathrm{Si}$ и угла падения света на образец вычисляются матрицы переноса [10] для $p$ - и $s$-поляризаций, а из них комплексные коэффициенты отражения $r_{p}$ и $r_{s}$. Далее из основного уравнения эллипсометрии (1) рассчитываются спектры $\psi$ и $\Delta$, которые сравниваются с экспериментальными спектрами, и осуществляется подгонка до получения наилучшей сходимости. К сожалению, использование этой однослойной модели при подгонке двух параметров $\left(d_{\mathrm{SiNWs}}\right.$ и $\left.f_{\text {voids }}\right)$ не дало хорошей сходимости.

Наилучшая подгонка спектров была получена с более сложной моделью, имеющей три слоя L1, L2, L3 (рис. 7,a). В рамках этой модели осуществлялась вариация 6 параметров и была достигнута хорошая

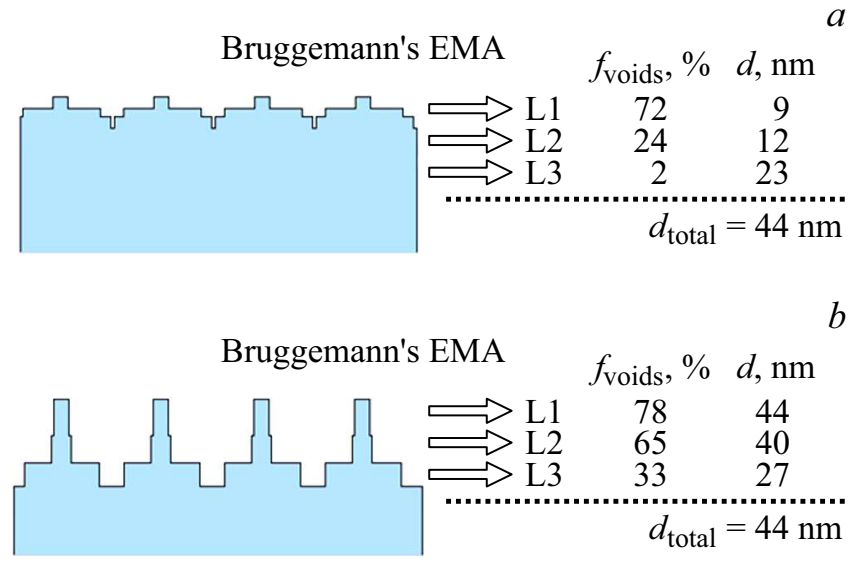

Рис. 7. Схематичная модель из трех слоев $L$ на подложке Si. Приведены наилучшие подгоночные параметры слоев (толщина $d$ и доля пустот $\left.f_{\text {voids }}\right)$ в рамках модели АЭСБ для травления в течение $t=5(a)$ и 10 с $(b)$.
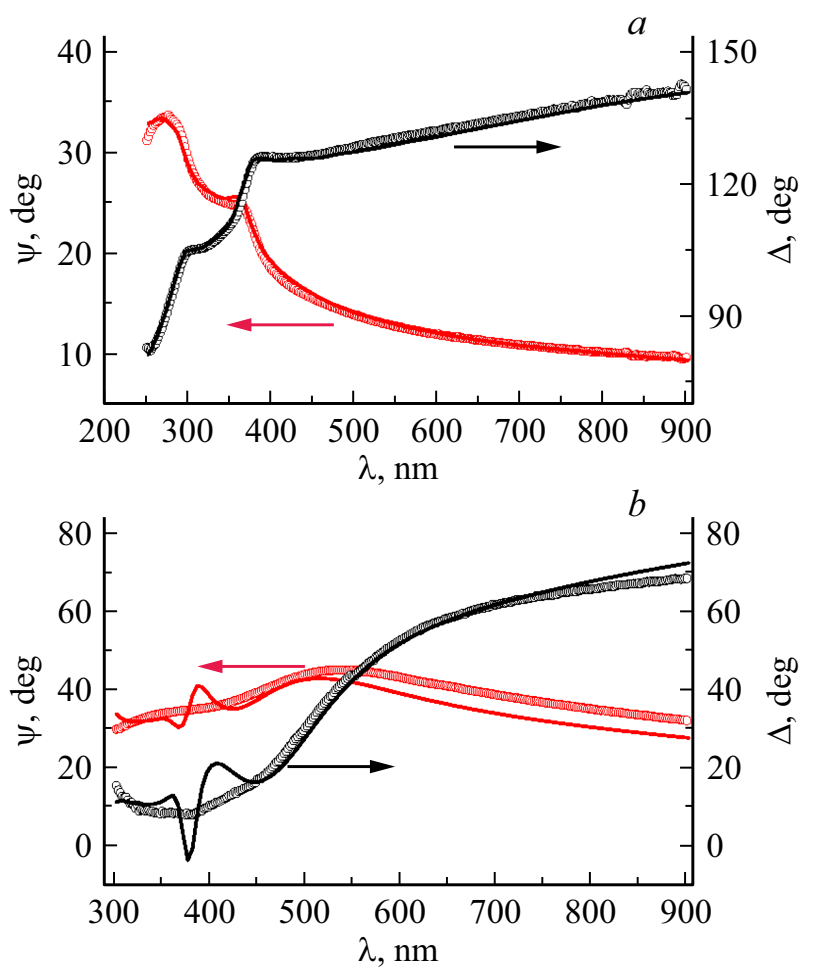

Рис. 8. Экспериментальные (точки) и расчетные (линии) спектры $\psi$ и $\Delta$ при угле падения $\varphi=70^{\circ}$ с вариацией параметров $L$-слоев из рис. 7 с использованием модели АЭСБ. Образцы после травления в течение $t=5(a)$ и $10 \mathrm{c}(b)$ (стадия 3 MCXT).

сходимость расчетных и экспериментальных $\psi$ и $\Delta$ во всем измеряемом диапазоне длин волн для образца с $t=5$ с (рис. $8, a)$. В этой оптической модели слой L1, расположенный на границе раздела с воздухом, имеет несколько иные значения $f_{\text {voids }}$ и долю $\mathrm{Si} f_{\mathrm{Si}}$, чем нижний слой L2. Слой L3, смежный с подложкой, может 
иметь долю $\mathrm{Si}$, несколько превышающую долю в слое L2 из-за геометрической неравномерности полученного интерфейса непосредственно в зоне каталитического травления, т.е. на самом дне. В рамках этой многослойной модели с использованием АЭСБ суммарная толщина трех слоев составила $d_{\mathrm{SiNWs}}=47 \mathrm{HM}$, при этом значения $f_{\text {voids }}$ в слое у подложки составили $2-24 \%$, тогда как в слое у границы с воздухом увеличились до $72 \%$. Таким образом, травление при $t=5$ с приводит к получению небольших углублений (увеличению шероховатости поверхности исходной пластины), при этом наночастицы серебра на этой стадии МСXТ не были погружены в кремний полностью.

Аналогичная модель (три L-слоя на подложке) (рис. 7,b) и процедура подгонки использовались для анализа эллипсометрических спектров образца, травленного в течение $t=10$ с с довольно хорошим согласием расчетных и экспериментальных данных в спектрах как $\psi$, так и $\Delta$, в диапазоне $\lambda=450-900$ нм (рис. $8, b)$. В то же время в расчетных спектрах наблюдаются значительные колебания и рассогласование с экспериментом в диапазоне $\lambda<450$ нм. Эффект рассогласования между расчетом и экспериментом можно объяснить сильным рассеянием и поглощением света структурой КНН, происходящим в ультрафиолетовой (УФ) области спектра. Такое же рассеяние наблюдали в эллипсометрических спектрах авторы [8], причем влияние рассеяния в их эксперименте захватывало не только УФ, но и видимую область с увеличением длины КНН. Соответственно существенно сокращался диапазон длин волн $\lambda$, который можно корректно использовать для подгонки по используемой модели. Полученная в нашей работе общая толщина всего слоя $\left(d_{\mathrm{SiNWs}}=111 \mathrm{Hм}\right)$ в результате подгонки с использованием трехслойной изотропной модели оказалась близкой к высоте слоя зародышей КНН, найденной из РЭМ-изображения на рис. $3, b$.

Из анализа параметров слоев $d_{\mathrm{SiNWs}}$ и $f_{\text {voids }}$ (рис. 7 ), удалось установить, что при травлении в течение $t=5 \mathrm{c}$ доля пустот составляла всего 2-72\%. Объяснение заключается в том, что размер пор-пустот сформировался на этом этапе МСXТ в соответствии с размером частиц $\mathrm{Ag}$, которые опускались в поры кремния. При $t=10 \mathrm{c}$ размер пор-пустот достигал размера частиц $\mathrm{Ag}$ и увеличивался в несколько большей степени из-за латерального травления, в результате чего доля пустот увеличилась до 33-78\%. Следовательно, каталитическое травление $c$-Si происходит не только под частицами, но до некоторой степени и в поперечном к вертикально формирующимся нитеобразным структурам направлении.

Таким образом, процесс МСXТ (рис. 2) на ранних этапах можно описать следующим образом. На первой стадии эксперимента был сформирован слой наночастиц $\mathrm{Ag}$ (средний размер 40-60 нм). На второй стадии после небольшого времени травления (5c) под частицами серебра происходит подтрав $\mathrm{Si}$ и частицы опускаются на глубину $\sim 30$ нм, причем бо́льшая часть объема частиц не погружается полностью в кремний. Таким образом, формируется слой частиц, частично заглубленных в кремний. При большей длительности травления $(10 \mathrm{c})$ частицы опускаются на глубину $\sim 110 \mathrm{Hм}$, полностью углубляясь в кремний. При травлении в течение $t=5 \mathrm{c}$ величина $f_{\text {voids }}$ составила только $2-24 \%$, так как размер пор-пустот сформировался только для того размера частиц $\mathrm{Ag}$, которые опустились в кремний, тогда как при большей продолжительности $(t=10 \mathrm{c})$ этот размер уже достиг размера частиц $\mathrm{Ag}$ и большего суммарного расширения пор-пустот, что привело к увеличению $f_{\text {voids }}$ до $33-78 \%$. Это значение $f_{\text {voids }}=0.78$ для L3 близко к данным, полученным нами из анализа топографии с помощью РЭМ (60-70\%).

\section{4. Заключение}

Исследованы образцы в трехстадийном процессе металл-стимулированного химического травления и особенности формирования нитеподобных наноструктур из $c$-Si.

$\mathrm{C}$ помощью спектральной эллипсометрии определены оптические характеристики получаемых структур в рамках двух моделей.

Во-первых, из экспериментальных эллипсометрических спектров были вычислены действительные и мнимые части псевдодиэлектрических функций слоев наночастиц $\mathrm{Ag}$ и наноструктур на основе $c$-Si в трехстадийном процессе MCXТ, проведено их сопоставление для каждой стадии. Так, на первой стадии процесса МСXТ слой самоорганизующихся наночастиц $\mathrm{Ag}$, нанесенный на подложку $\mathrm{Si}$ химических методом, служит в качестве маски-катализатора в MCXТ и имеет диэлектрическую функцию с характерным пиком плазмонного резонанса в УФ части спектра. На второй и третьей стадиях процесса МСXТ анализировались изменения спектральных зависимостей $\varepsilon$ (с наночастицами $\mathrm{Ag}$ и без них), связанные с критическими точками в структуре $c$-Si и резонансным пиком Ag. Так, при небольшой продолжительности травления в спектрах $\varepsilon$ явно доминирует слой частиц $\mathrm{Ag}$, тогда как при более длительном травлении образующийся слой КНН оптически „экранирует“ отклик от находящихся в нем наночастиц $\mathrm{Ag}$.

Во-вторых, на основании структурных исследований слоев наноструктур Si с помощью РЭМ была использована оптическая многослойная модель (включающая приближение эффективной среды Бруггемана) и путем подгонки определены входящие в нее параметры: толщина и фракция пустот каждого из слоев. Полученные экспериментальные данные (оптические и структурные) хорошо согласуются между собой, а их интерпретация позволила выявить особенности каталитического травления кремния на ранних этапах используемой технологии MCXТ. Так, вначале формируются углубления (шероховатости) с размерами, сопоставимыми с размерами наночастиц серебра (30-50 нм), а при увеличении продолжительности травления образуются зародыши нанонитей 
из $c$-Si с длиной, достигающей 100-120 нм. Результаты работы будут полезны для создания нанослоев из КНН с заданной топологией и композитных структур на их основе с различными функциональными компонентами.

Исследование выполнено при финансовой поддержке РФФИ в рамках научного проекта № 17-02-01116 А с использованием оборудования центра коллективного пользования „Материаловедение и диагностика в передовых технологиях“.

\section{Список литературы}

[1] Ю.А. Жарова, В.А. Толмачев, С.И. Павлов, Е.В. Гущина. ФТП, 52 (3), 333 (2018).

[2] Min Lv, Shao Su, Yao He, Qing Huang, Wenbing Hu, Di Li, Chunhai Fan, Shuit-Tong Lee. Adv. Mater., 22 (48), 5463 (2010).

[3] Hee Han, Zhipeng Huang, Woo Lee. Nanotoday, 9, 271 (2014).

[4] L.A. Osminkina, K.A. Gonchar, V.S. Marshov, K.V. Bunkov, D.V. Petrov, L.A. Golovan, V.A. Sivakov, V.Yu. Timoshenko. Nanoscale Res. Lett., 7, 524 (2012).

[5] Ellipsometry at the Nanoscale, ed. by M. Losurdo, K. Hingerl (N.Y.-Dordrecht-London, Springer, 2013) p. 1.

[6] E. Agocs, P. Petrik, S. Milita, L. Vanzetti, S. Gardelis, A.G. Nassiopoulou, G. Pucker, R. Balboni, M. Fried. Thin Sol. Films, 519, 3002 (2011).

[7] Л.А. Головань, В.Ю. Тимошенко, П.К. Кашкаров. Успехи физ. наук, 177 (6), 619 (2008).

[8] B. Fodor, T. Defforge, E. Agocs, M. Fried, G. Gautier, P. Petrik. Appl. Surf. Sci., 421, 397 (2017).

[9] В.А. Швец, Е.В. Спесивцев, С.В. Рыхлицкий, Н.Н. Михайлов. Рос. нанотехнол., 4, 201 (2009) [Nanotechnologies in Russia, 4, 201 (2009)].

[10] Р. Аззам, Н. Башара. Эллипсометрия и поляризованный cвет (М., Мир, 1981) с. 316 [Пер. с англ.: R.M.A. Azzam, N.M. Bashara. Ellipsometry and Polarized Light (Amsterdam-N.Y.-Oxford, North-Holland Publ. Co, 1977).

[11] D.E. Aspnes. Thin Sol. Films, 89, 249 (1982).

[12] Handbook of Optical Constants of Solids, ed. by Palik (N.Y., Academic Press, 1985).

[13] D.A.G. Bruggeman. Ann. Phys. (Leipzig), 416, 636 (1935).

Редактор Л.В. Шаронова

\section{Optical and structural properties of nanostructures of $\mathrm{Ag}$ and $c$-Si formed in the process of metal-assisted chemical etching of silicon}

\author{
Yu.A. Zharova, V.A. Tolmachev, S.I. Pavlov \\ loffe Institute, \\ 194021 St. Petersburg, Russia
}

\begin{abstract}
The work, consisting of two parts, is devoted to the study of peculiarities of the three-step process of the metal-assisted chemical etching (MACE) of silicon, used for fabrication of silicon nanowires (SiNWs). Earlier, a layer of self-assembling silver nanoparticles deposited by the chemical method from a solution on the surface of single-crystal silicon ( $c$-Si) (the 1st stage of MACE) was investigated, and in the present work - $\mathrm{Si}$ nanostructures formed at the 2nd and 3rd stages. Using spectroscopic ellipsometry (wavelengths $\lambda=250-900 \mathrm{~nm}$ ), pseudoelectric functions were determined and a comparison was made for all three stages of the MACE process. In addition, for Si nanostructures, the parameters of the sublayers (the thickness and the void fraction) are calculated in the multilayer optical model using the Bruggeman's effective

medium approximation and fitting procedures.
\end{abstract}

